\title{
Cellular pattern of photosynthetic gene expression in developing maize leaves
}

\author{
Jane A. Langdale, Beverly A. Rothermel, and Timothy Nelson \\ Department of Biology, Yale University, New Haven, Connecticut 06511 USA
}

Leaf development in $\mathrm{C} 4$ plants such as maize involves the differentiation of two photosynthetic cell types [bundle sheath (BS) and mesophyll (M)] to form Kranz-type leaf anatomy. This cellular dimorphism partitions photosynthetic activities so that each enzyme of the $\mathrm{C} 4$ pathway accumulates only in the appropriate cell type. We have exploited this property to study BS and $M$ cell interactions in developing maize leaves. Our previous studies showed that $\mathrm{C} 4$ proteins appear concurrently with the appearance of Kranz anatomy. To look at earlier events in BS and $M$ cell development we have used three of the corresponding C4 mRNAs as cell-specific markers. We have followed, in situ, the accumulation of malic enzyme (ME), phosphoenolpyruvate carboxylase (PEPCase), and ribulose bisphosphate carboxylase (RuBPCase) mRNAs in developing leaves of both normal and mutant argentia $(a r)$ maize. We have isolated a partial cDNA clone for maize ME to examine ME mRNA expression. We show that throughout the development of light-grown seedlings, all three mRNAs accumulate in a cell-specific fashion in both normal and ar leaves. The pattern of C4 mRNA accumulation longitudinally along the veins, laterally across the leaf, and locally around individual veins reveals the spatial and temporal sequence of $B S$ and $M$ cell development. BS cell-specific mRNAs accumulate around developing veins before Kranz anatomy is evident morphologically. Our analysis of the ar mutant, in which C4 mRNA appearance is delayed relative to the appearance of Kranz anatomy, demonstrates first that BS and $M$ cells develop in clusters across the leaf blade and second that BS cells surrounding any individual vein are activated asynchronously. We discuss our results in relation to models and mechanisms of BS and $M$ cell development.

[Key Words: Leaf development; C4 photosynthesis; maize; in situ hybridization]

Received July 6, 1987; revised version accepted November 20, 1987.

Leaf development in all vascular plants is initiated within the vegetative shoot meristem. In graminaceous plants, subsequent cell divisions and elongation occur primarily from a basal intercalary meristem producing a gradient of cells along the leaf, with the youngest at the base and the oldest at the tip (Sharman 1942). Successive transverse sections of a leaf therefore provide synchronized populations of cells at different developmental stages. This property has been utilized to study various aspects of leaf development in both $\mathrm{C} 3$ plants such as barley (Viro and Kloppstech 1980), oats (Taylor and Mackender 1977), and wheat (Dean and Leech 1982; Aoyagi and Bassham 1986a) and C4 plants such as maize (Leese and Leech 1976; Baker and Leech 1977; Williams and Kennedy 1978; Miranda et al. 1981; Martineau and Taylor 1985; Aoyagi and Bassham 1986b).

In $\mathrm{C} 4$ plants photosynthetic development is more complex than in C3 plants due to chloroplastic and cellular dimorphism. Photosynthesis in C3 plants requires only one photosynthetic cell type, whereas C4 plants rely on Kranz-type leaf anatomy in which the veins running the length of the leaf are surrounded by two layers of photosynthetic cells (Brown 1975). The inner bundle sheath (BS) cells form a single layer around each vein, and the outer mesophyll (M) cells form a layer that is in contact with the epidermis. Although the photosynthetic BS and M cells arise from two separate cell lineages (procambium and ground meristem, respectively) (Dengler et al. 1985; M. Freeling, pers. comm.), when fully differentiated they must interact to fix $\mathrm{CO}_{2}$ (for a review, see Edwards and Huber 1981). The C4 pathway requires malate dehydrogenase $(\mathrm{MDH})$, phosphoenolpyruvate carboxylase (PEPCase), and pyruvate phosphate dikinase (PPdK) activities in the $M$ cells and malic enzyme (ME) and ribulose bisphosphate carboxylase (RuBPCase) activities in the BS cells. These enzymes are synthesized cytoplasmically in a cell-specific manner and subsequently subcompartmentalized such that $\mathrm{MDH}$ and PPdK are found in $M$ cell chloroplasts, PEPCase in $M$ cell cytoplasm, and ME and RuBPCase in BS cell chloroplasts (Edwards and Huber 1979; Broglie et al. 1984). PPdK has also been detected in BS cell chloroplasts, but its function in these cells is unknown (Aoyagi and Nakamoto 1985).

The enzymes associated with $\mathrm{C} 4$ metabolism have been used previously as cell-specific markers to analyze patterns of leaf development (Mayfield and Taylor 1984; Nelson et al. 1984; Aoyagi and Bassham 1986b; Langdale et al. 1987). Immunolocalization assays have shown that BS and $M$ cells accumulate C4 enzymes in the same 
order as the leaf vasculature differentiates (Langdale et al. 1987). BS and $M$ cells around the median vein mature first (acropetally); cells around the lateral veins then develop both acropetally and basipetally. Finally, cells around the intermediate veins mature basipetally. This is the same order in which the cells become morphologically differentiated (Esau 1942; Sharman 1942; Russell and Evert 1985), which is suggestive of a requirement for some degree of morphological distinction coincident with or prior to $\mathrm{C} 4$ enzyme accumulation. The relative timing of these events cannot be distinguished using $\mathrm{C} 4$ proteins as cell-specific markers because we have shown previously that $\mathrm{C} 4$ proteins are detected concurrently with the appearance of Kranz anatomy (Langdale et al. 1987). To study earlier developmental events, the corresponding C4 mRNAs can be used as markers for each cell type. One report showed that RuBPCase mRNAs accumulate prior to morphological differentiation of BS cells, but PEPCase mRNA accumulates only when Kranz anatomy is fully apparent (Martineau and Taylor 1985). These Northern blotting experiments, however, provided only an evaluation of mRNA accumulation within a section of a leaf and not within individual cells of that section.

In this paper we examine the cellular expression of $\mathrm{C} 4$ mRNAs during leaf development. We show the spatial pattern of C4 mRNA accumulation throughout the leaf and demonstrate that fully differentiated Kranz anatomy is not required for the expression of all the C4 mRNAs. Our analysis of the maize mutant argentia $(a r)$ (Eyster 1933) shows that BS and $M$ cells always develop in clusters across the leaf, which is indicative of interactions between the two cell types during development. We also use this mutant to show that BS cells surrounding any individual vein can accumulate $\mathrm{C} 4$ mRNAs asynchronously.

\section{Results}

\section{Isolation of a ME cDNA clone}

To study the accumulation of ME mRNA in parallel with other C4 mRNAs, we cloned a partial maize cDNA as described in Methods. The identity of the cDNA was confirmed by hybrid selection translation reactions with the cDNA subclone pBF1 (Fig. 1). The selection-translation product (lane 2) was approximately $75 \mathrm{kD}$, which corresponds to the size of the ME precursor protein reported previously (Collins and Hague 1983).

\section{Cell-specific accumulation of $C 4 \mathrm{mRNAs}$ in normal leaves}

RuBPCase and PEPCase mRNAs have been detected previously in specific cell types of maize leaves (Link et al. 1978; Martineau and Taylor 1986). To investigate the size, abundance, and cellular location of ME mRNA, we hybridized the ME cDNA probe to poly $(\mathrm{A})^{+}$RNA isolated from whole leaf tissue and from separated cells (Fig. 2). PEPCase and RuBPCase small subunit (Ssu)

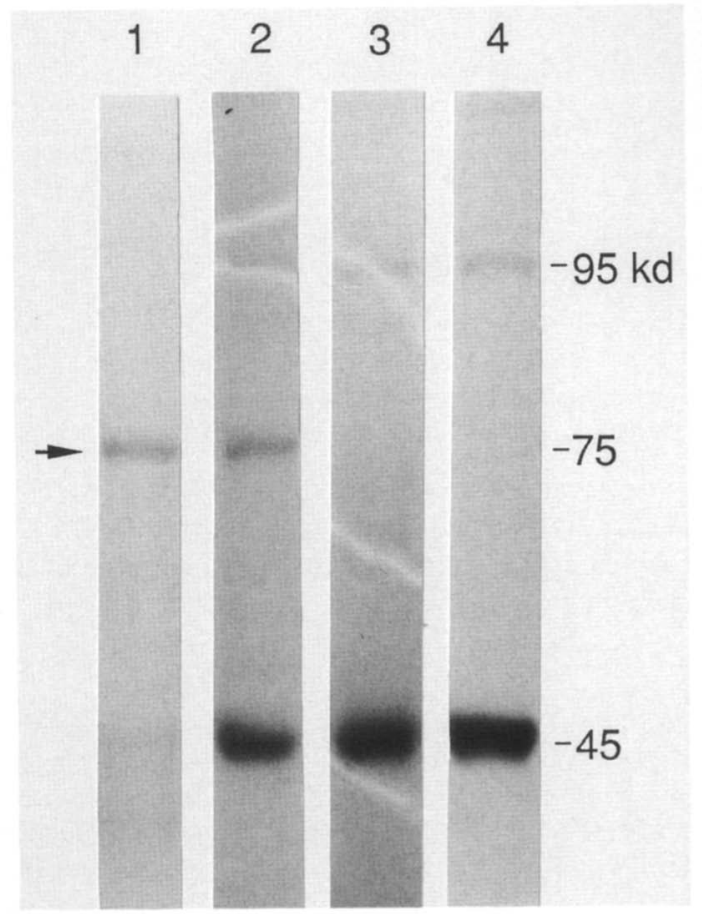

Figure 1. Hybrid-selection translation of ME cDNA. Lanes exhibit in vitro translation products from reactions with total leaf poly $(\mathrm{A})^{+}$RNA (immunoprecipitated with $\mathrm{ME}$ antiserum) (lane 1), RNA hybrid selected with the ME cDNA (lane 2), RNA hybrid selected with pBS|+ | vector DNA (lane 3), and no RNA added (lane 4). $\rightarrow$ ) The $75 \mathrm{kD}$ ME precursor protein. The 95and $45-\mathrm{kD}$ polypeptides are nonspecific products of the translation reaction.

cDNA probes were used as controls to check the purity of the cell preparations. We detected a single ME transcript, $2.2 \mathrm{~kb}$ in size, BS cell specific, and less abundant relative to PEPCase and Ssu transcripts.

\section{Cellular localization of C4 mRNAs in normal leaves}

Each C4 mRNA exhibited a distinct spatial distribution throughout the leaf. This cellular localization of $\mathrm{C} 4$ mRNAs was examined by in situ hybridization of labeled antisense RNA probes to serial sections of normal leaf blades (Fig. 3a). The cell-type distribution is consistent with Northern blot data; ME and RuBPCase large subunit (Lsu) transcripts were localized in BS cells, and PEPCase mRNA was detected in M cells. Ssu transcripts were also restricted to BS cells (data not shown). Because all probes were labeled to approximately the same specific activity, the relative abundance of each of these messages can be estimated by comparing autoradiograph exposure times. Lsu assays were autoradiographed for 12 $\mathrm{hr}$, whereas ME, PEPCase, and Ssu reactions were autoradiographed for $72 \mathrm{hr}$. Control reactions using sense labeled RNA probes exhibited only a low level of nonspecific hybridization (Fig. 3b).

Because maize leaves present a developmental gradient from base (young) to tip (old) (Sharman 1942), we examined the accumulation of specific mRNAs at pro- 


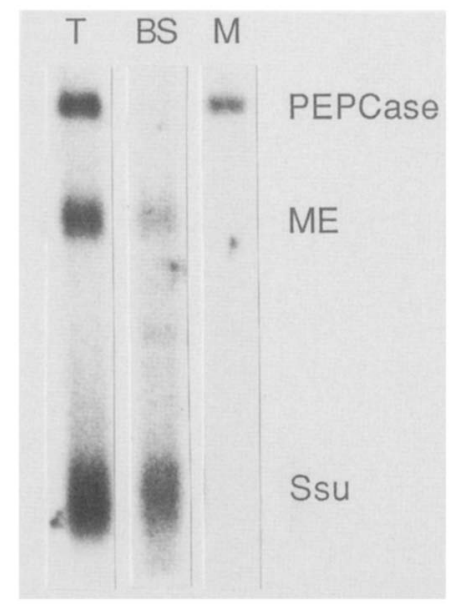

Figure 2. Northern blot analysis of PEPCase, ME, and Ssu transcripts $\left\{3.4,2.2\right.$, and $1.0 \mathrm{~kb}$, respectively). Poly $(\mathrm{A})^{+}$RNA $(2 \mu \mathrm{g})$ prepared from whole leaf tissue $(T)$ was compared with $0.5 \mu \mathrm{g}$ poly $(\mathrm{A})^{+} \mathrm{RNA}$ isolated from purified BS and M cells. DNA probes were labeled to the same specific activity. Nonspecific crosshybridization of the Ssu cDNA clone to rRNA was evident in the BS RNA preparation. This preparation contained the most rRNA, as judged by ethidium bromide staining.

gressive locations along the leaf. We found that each $\mathrm{C} 4$ mRNA is restricted to the appropriate cell type throughout developmental changes in abundance. Serial sections of six samples taken from throughout the developing third leaf of a 21-day-old plant were hybridized with Lsu, Ssu, ME, or PEPCase probes. No specific hybridization signal was obtained with any of the probes in sections taken from the basal meristem region (data not shown). Results obtained when the other five sections were hybridized to the Lsu probe are shown in Figure 4. Hybridization signal clearly decreases from the base of the leaf blade to the tip (Fig. $4 a-d$ ). In the leaf sheath, the third and fourth leaves contribute most of the hybridization signal (Fig. 4g). This decrease in hybridization signal toward the outer edge of the sheath (Fig. 4h) indicates that older leaves of the sheath contain less Lsu mRNA than younger leaves. Kranz anatomy can be distinguished in these younger leaves but is not fully differentiated, as determined by the relatively thin cell walls and low number of mature chloroplasts (Fig. 4e). Some nonspecific hybridization was observed in control sections of leaf sheaths hybridized with sense labeled RNA probes (Fig. 4f). However, specific hybridization of Lsu mRNA was clearly detected above background (Fig. 4g). The developmental accumulation pattern of Ssu mRNA was identical to that shown (data not shown). ME and PEPCase mRNAs were not detected as early as Lsu and Ssu mRNAs (data not shown). In agreement with published data (Martineau and Taylor 1985), these results show that RuBPCase mRNAs accumulate prior to PEPCase mRNAs.

The sensitivity of in situ hybridization permitted the examination of $\mathrm{C} 4$ distribution prior to the appearance of Kranz anatomy. Serial sections of the meristematic region of 7-day-old seedlings were hybridized with Lsu, Ssu, ME, and PEPCase RNA probes. The results ob- tained for Lsu and PEPCase are shown in Figure 5. Specific hybridization of Lsu mRNA was only detected in the first leaf, in cells around major veins. No hybridization signal was detected in the coleoptile. Figure $5, a-d$, shows serial sections of the region around one developing vein. Kranz anatomy is not clearly defined, yet Lsu mRNA is detected above background in BS progenitor cells (Fig. 5b). Similar results were obtained with ME and Ssu, but hybridization signals were not as intense, particularly in the case of ME where signal was barely detectable (data not shown). Figure 5 d shows that PEPCase hybridization could not be detected above background in these sections. Although this may simply represent the limits of our detection method, these data lend further support to the idea that BS cell-specific mRNAs accumulate before $M$ cell-specific mRNAs.

\section{Cellular localization of C4 mRNAs in ar leaves}

The ar mutation delays normal photosynthetic development when mutant seedlings are grown below $22^{\circ} \mathrm{C}$. This delay permits examination of the progressive activation of BS and $M$ cells in leaves with well-established Kranz anatomy. In normal ar leaves of the same age, C4 protein levels (Langdale et al. 1987), poly|A $)^{+}$RNA, and C4 mRNA levels (data not shown) are lower in the mutant. These lower levels correspond to those seen in normal leaves at an earlier age. Under our standard growth conditions, sibling ar seedlings exhibited the phenotype illustrated in Figure 6. The third leaves of most seedlings were predominantly white with a green midrib, fine green stripes at the base of the leaf, and prominent green stripes at the tip. Most experiments were carried out using leaves with this phenotype. ar leaves green in the same order as both the leaf vasculature differentiates and C4 enzymes accumulate in normal leaves (Langdale et al. 1987). Striped ar leaves consequently reflect a later stage in photosynthetic development than do predominantly white leaves. Where indicated, experiments were also carried out using striped ar leaves to characterize this later stage in development.

We examined the spatial distribution of C4 mRNAs in ar leaves by hybridization of serial leaf sections with Lsu, ME, PEPCase, and Ssu probes. In both predominantly white and striped ar leaves mRNA accumulation patterns reflected our previously determined pattern of protein accumulation (Langdale et al. 1987). Compartmentalization of ME, PEPCase, and RuBPCase mRNAs in ar leaves was the same as that in normal leaves. mRNAs accumulate first in cells surrounding the median vein, then in cells surrounding lateral veins, and finally in cells surrounding intermediate veins /data not shown).

To determine whether the delayed pattern of $\mathrm{C} 4$ enzyme accumulation observed in ar leaves is controlled at the level of RNA or protein accumulation, we compared the cellular localization of mRNA and protein in these leaves. Serial sections of normal control leaves and predominantly white ar leaves were reacted with ME antibody and ME- and Lsu-labeled antisense RNA probes 


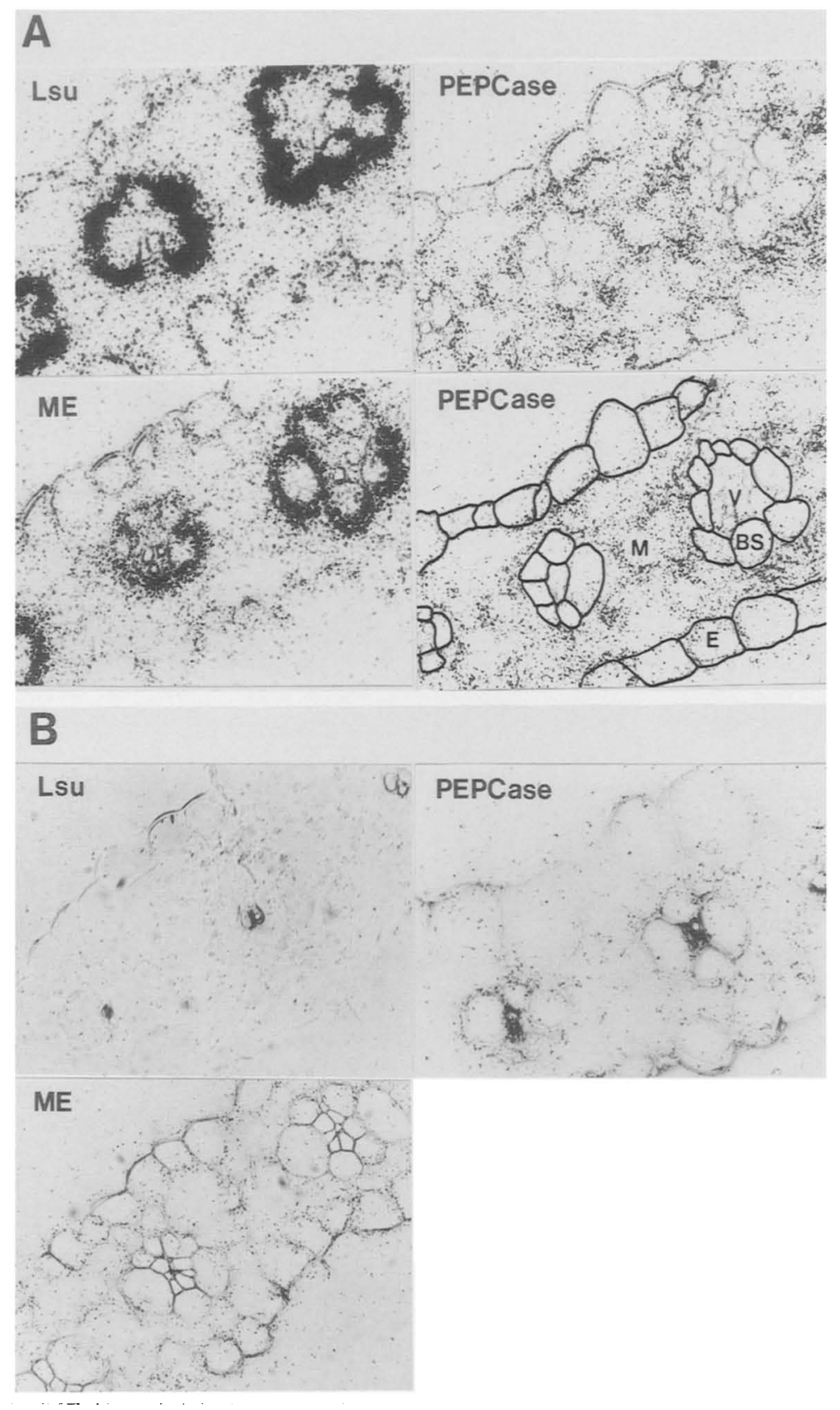

Figure 3. In situ hybridization to Lsu, PEPCase, and ME mRNAs in serial sections of a normal leaf blade. Exposure times were 12,72 , and $72 \mathrm{hr}$, respectively. The overlay in $A$ emphasizes the $M$ cell-specific PEPCase signal and indicates veins (V), epidermal (E), M, and BS cells. $(A \mid$ Sections hybridized with labeled antisense RNA probes. Because plant cells are highly vacuolated, grains are seen only in the thin layer of cytoplasm abutting the cell walls. $(B)$ Control sections hybridized with labeled sense RNA probes. Magnification $A$, $B, 180 \times$.

(Fig. 7). In normal leaves (Fig. 7a,c,e), ME protein, ME mRNA, and Lsu mRNA were detected in all BS cells. In ar leaves (Fig. 7b,d,f), however, both protein and mRNA were absent from BS cells surrounding one vein.

The relative rates of $\mathrm{BS}$ and $\mathrm{M}$ cell development in ar leaves were compared with respect to Lsu and PEPCase mRNA accumulation patterns. Serial sections from the middle of an expanded leaf blade were hybridized to Lsu and PEPCase probes (Fig. 8). In the section shown, Lsu transcripts were detected only in BS cells around major veins (example indicated with arrow), whereas PEPCase transcripts could be seen along the whole section. We have never observed Lsu mRNA in a BS cell that was not adjacent to a PEPCase mRNA-containing $M$ cell. These data suggest that in ar leaves, BS cell development is delayed with respect to $M$ cell development at the level of C4 mRNA accumulation. The delayed accumulation of Lsu mRNA in BS cells illustrated that this message does not appear simultaneously in all BS cells surrounding any particular vein. One or two cells can contain high levels of message while adjacent cells contain nondetectable amounts (Fig. 8). This result was also observed 

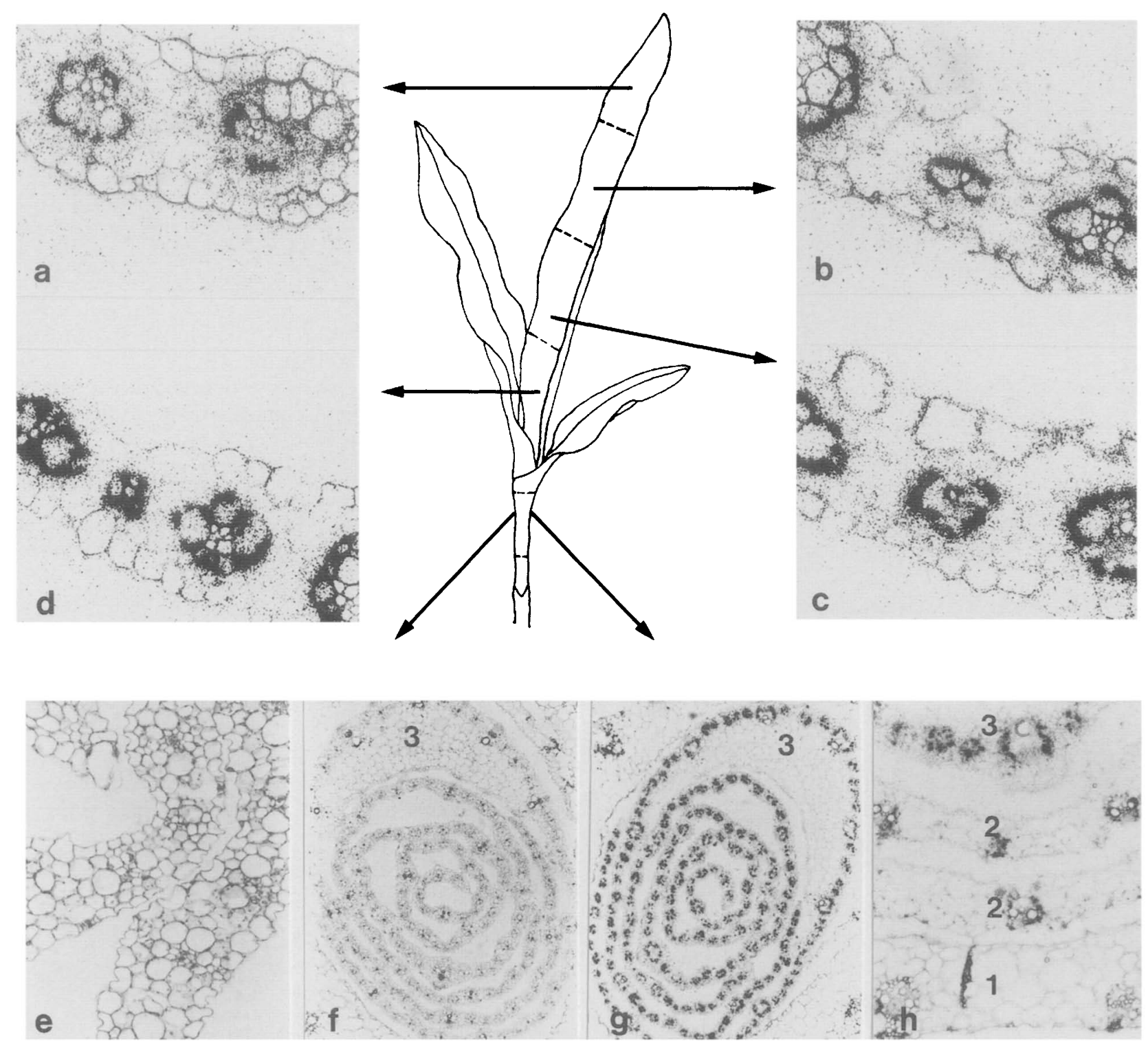

Figure 4. Accumulation of Lsu mRNA in a developing maize leaf. $(a-d)$ Leaf blade sections taken from the areas indicated on the plant. Magnification, $120 \times .(e-h)$ Serial sections of the leaf sheath. (e) Fast Green-stained section of the fourth leaf. Magnification, $80 \times .(f)$ Control section of the leaf sheath hybridized with sense labeled Lsu RNA. Magnification, $40 \times$. $(g)$ Section of the leaf sheath hybridized with antisense labeled Lsu mRNA. Magnification, $40 \times$. (h) Partial section of the leaf sheath showing the first, second, and third leaves. Magnification $80 \times$. Autoradiographs were exposed for $12 \mathrm{hr}$. Samples were taken from $1-4 \mathrm{~cm}(e-h), 7-10 \mathrm{~cm}(d), 12-15$ $\mathrm{cm}(c), 17-20 \mathrm{~cm}(b)$, and $22-25 \mathrm{~cm}|a|$ above the apical shoot meristem. The 1-4 $\mathrm{cm}$ sample was leaf sheath material and the 7-10 $\mathrm{cm}$ sample was nonexpanded leaf blade material. Leaf numbers are as indicated.

with Ssu and ME mRNAs and has been seen occasionally in normal leaf sections (data not shown).

\section{Discussion}

The development of dimorphic photosynthetic cell types in maize is crucial because the functioning of the C4 photosynthetic pathway relies on correct partitioning of the participating enzymes. Moreover, this relationship between form and function appears to be uncompromising because all nonsucculent plants that utilize the $\mathrm{C} 4$ pathway exhibit Kranz anatomy. The regulation of this association, however, remains poorly understood. We discuss some relevant questions with reference to our data.

At what level of regulation is the cell-specific accumulation of C4 enzymes determined? We have shown that throughout the development of light-grown tissue C4 mRNAs are compartmentalized in the cell types that accumulate their respective proteins. Therefore, compartmentalization of $\mathrm{C} 4$ enzymes must be controlled at the level of mRNA accumulation, either by transcriptional control or differential stabilization of C4 mRNAs. The relative amounts of each message, however, need not be regulated in this manner. For example, in agreement with published reports (Sheen and Bogorad 1986), 


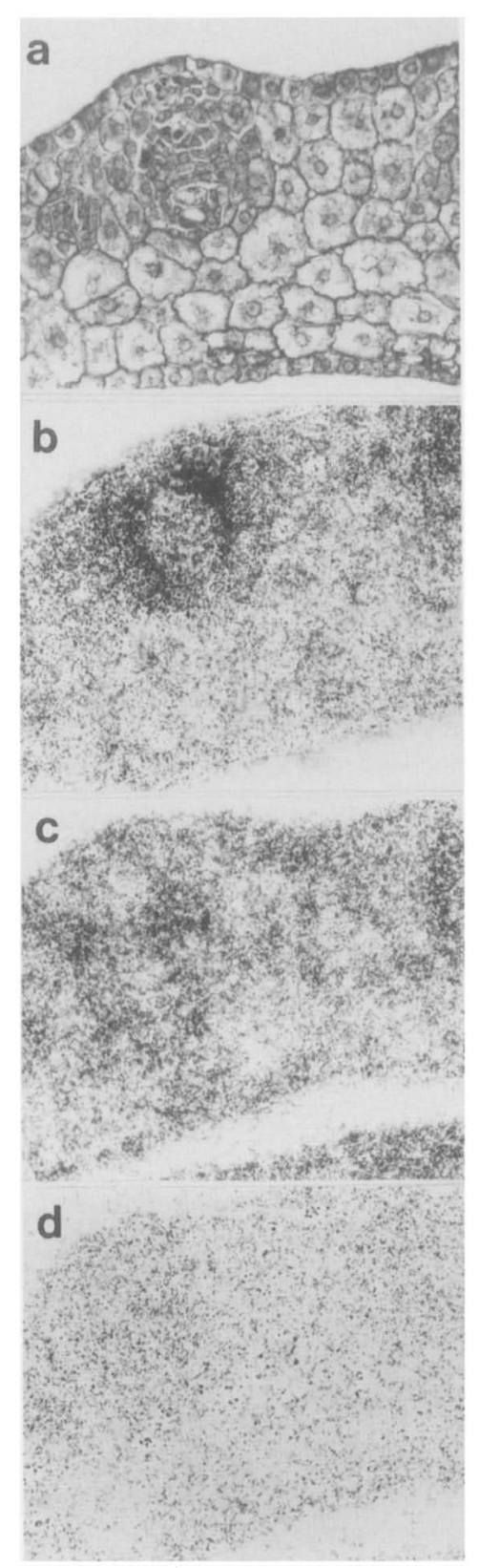

Figure 5. Localization of Lsu and PEPCase mRNAs in leaf primordia of a 7-day-old seedling. (a) The region around a single developing vein in the first leaf primordia stained with Fast Green. Magnification $212 \times .(b, c)$ Serial sections of the region shown in $a$ hybridized with Lsu antisense and sense labeled RNA probes, respectively, and autoradiographed for 2 days. $(d)$ Serial section of the same region hybridized to a PEPCase-la. beled antisense RNA probe and autoradiographed for 9 days.

we observe that Lsu transcripts are always much more abundant than Ssu transcripts. In this case, because protein subunits are maintained in equal numbers, posttranscriptional or translational control of one or both of these messages must occur.

Are individual BS and $\mathrm{M}$ cells determined to accumulate C4 mRNAs in a specific order? Our data show that BS cells around any particular vein are activated asynchronously. Moreover, a single cell can accumulate a large amount of $\mathrm{C} 4 \mathrm{mRNA}$ before accumulation is initiated in neighboring cells. In normal leaves we have seen BS cells that contain C4 mRNAs in the absence of neighboring $\mathrm{C} 4 \mathrm{mRNA}$-containing $M$ cells, but we have observed the opposite situation in ar leaves. These facts all indicate that individual cells have a certain degree of autonomy with respect to C4 mRNA accumulation.

What degree of morphological differentiation is required prior to $\mathrm{C} 4$ mRNA accumulation? The longitudinal distribution of $\mathrm{C} 4 \mathrm{mRNAs}$ along the veins of the leaf indicates a preference, but not an absolute requirement, for fully differentiated Kranz anatomy. Although the relative amounts of $\mathrm{C} 4 \mathrm{mRNAs}$ differ, each exhibits an accumulation peak in the nonexpanded leaf blade. This is the point where Kranz anatomy is fully differentiated morphologically (Miranda et al. 1981). Furthermore, once the leaf blade is fully expanded, levels of $\mathrm{C} 4$ mRNAs decrease in the leaf sheath. BS and $\mathrm{M}$ cells in the leaf sheath never achieve the fully differentiated state of cells in the leaf blade. C4 mRNAs were not detected in coleoptiles where Kranz anatomy is absent. However, in situ analysis of young leaf primordia suggests that $\mathrm{Kranz}$ anatomy is not absolutely required for expression of some of the C4 mRNAs. We show that BS cell-specific mRNAs can accumulate in tissues where Kranz anatomy is not morphologically differentiated. The cells in these tissues contained no chloroplasts, as visualized using the light microscope.

Do BS and $M$ cells share a common developmental pathway because they interact so closely in the mature leaf? Electron microscope studies of the meristematic region of sugar cane have shown that in the early stages of leaf development in this plant, BS and M cell chloroplasts are morphologically indistinguishable (Laetsch and Price 1969). Clearly at the level of C4 mRNA accumulation in maize, the two cell types are distinguishable very early in leaf development because Lsu mRNA is clearly detected in BS progenitor cells. Although the earliest studies with maize suggested that BS and $M$ cells could arise from the same clonal origin (Esau

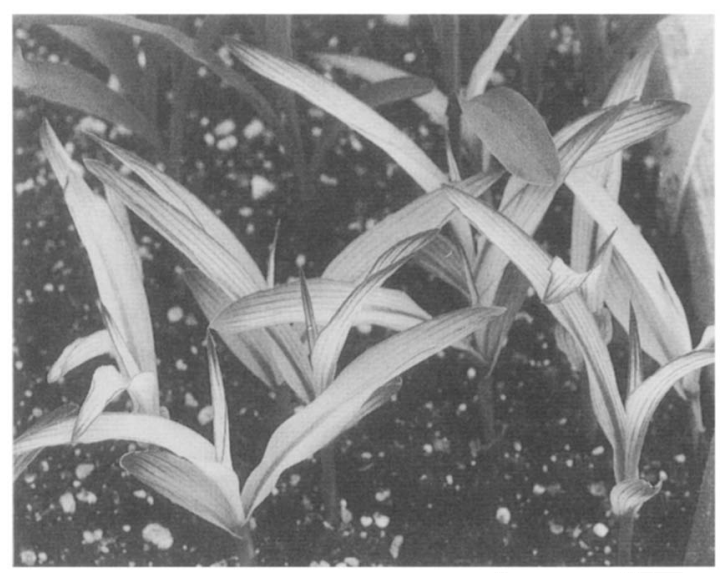

Figure 6. Phenotypes exhibited by ar (foreground) and normal (background) maize seedlings grown under identical conditions. 
1942; Sharman 1942), more recent studies contradict this viewpoint, suggesting that BS cells arise from procambial meristems, whereas $M$ cells arise from the ground meristem (Dengler et al. 1985; M. Freeling, pers. comm.).

Is there any evidence for cell-cell interactions across the leaf during early development of vascular bundles? Because BS cells arise from procambial meristems and C4 mRNAs accumulate in BS cells in the same order as the leaf vasculature differentiates, it is implicated that the positioning of BS cells is determined by vein posi- tion. In normal leaves the accumulation of BS cell-specific mRNAs precedes the accumulation of $M$ cell-specific messages. These data suggest to us a BS- $\mathrm{M}$ cell interaction early in development that probably originates from, and is limited by, the developing vein. This idea is supported by our analysis of mutant ar leaves, in which BS and $M$ cells always mature in clusters, initially around the oldest veins. However, two discrepancies exist. First, vascular development in ar leaves does not appear to be delayed and therefore cannot be limiting BS and $M$ cell development per se. However, a mutation af-

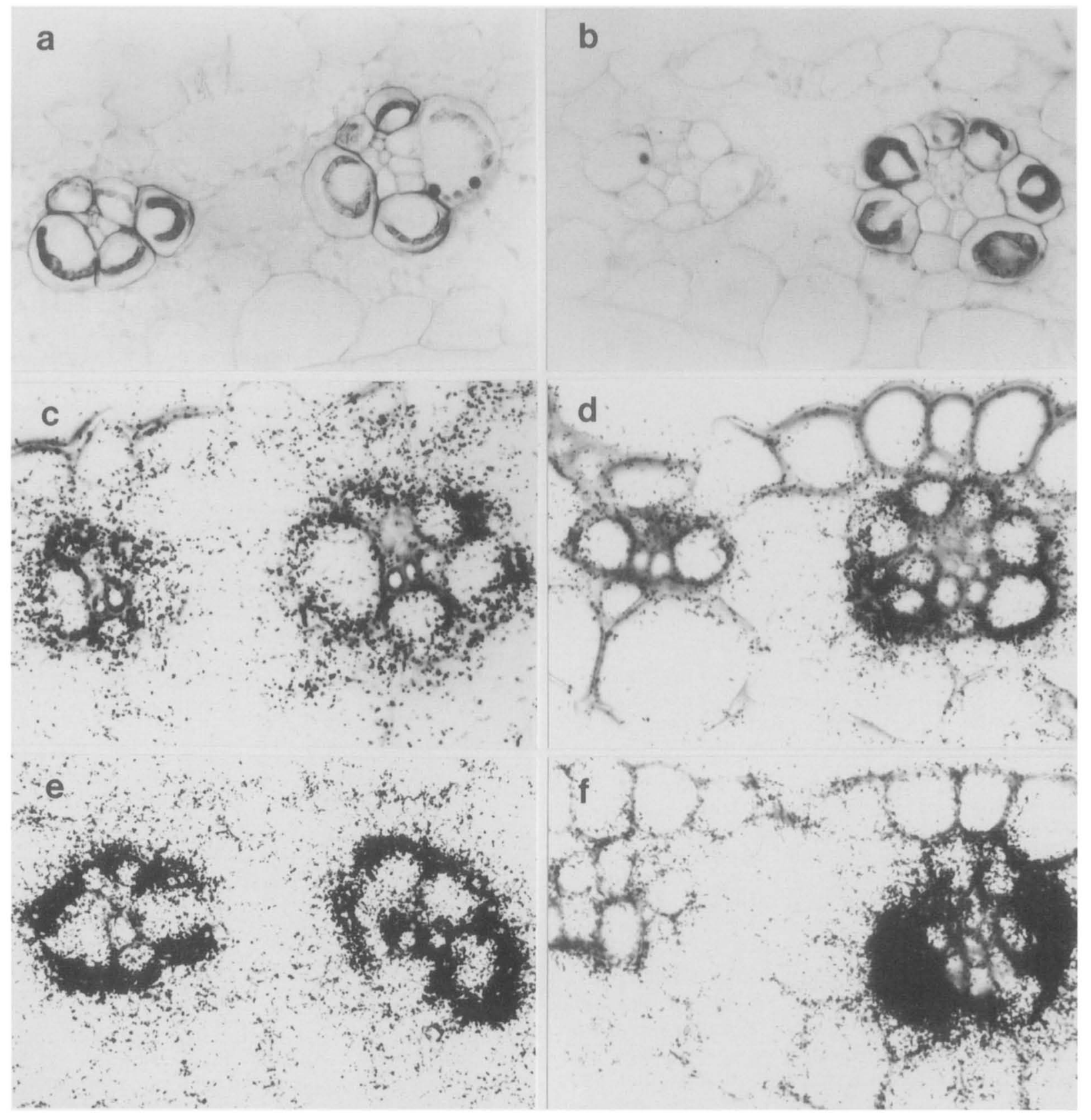

Figure 7. In situ localization of $\operatorname{ME}$ protein $(a, b)$ and $\operatorname{ME}(c, d)$ and Lsu $(e, f)$ mRNAs in serial sections of normal $\langle a, c, e\rangle$ and $a r(b, d, f\rangle$ leaf blades. Autoradiographs were exposed for $72 \mathrm{hr}$ (ME) or $12 \mathrm{hr}$ (Lsu). Magnification, $240 \times$. 

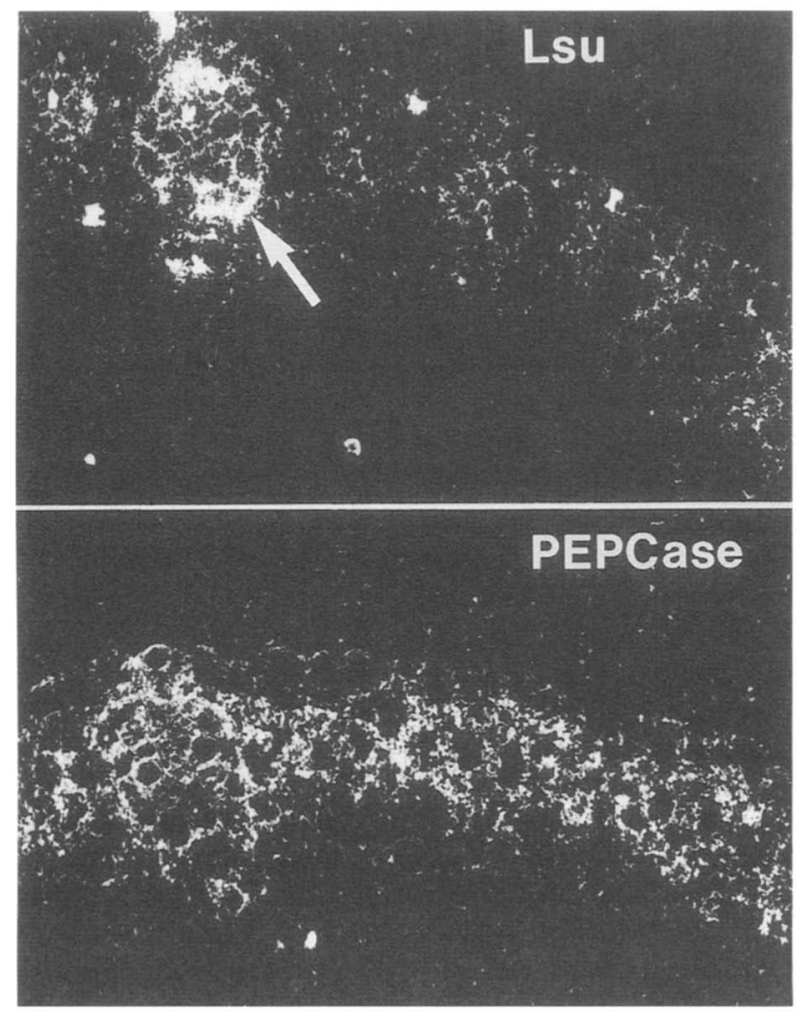

Figure 8. The distribution of Lsu and PEPCase mRNAs in serial sections of ar leaves. Autoradiographs were exposed for 12 and $72 \mathrm{hr}$, respectively. Magnification, $60 \times$, using dark-field microscopy. $\rightarrow$ The Lsu hybridization signal, seen in only 4 out of the $11 \mathrm{BS}$ cells surrounding the vein.

fecting transport of a specific metabolite is still possible. Second, in ar leaves the specific order of BS and M cell differentiation around any particular vein is altered. The accumulation of BS cell-specific transcripts is delayed with respect to the accumulation of $M$ cell-specific messages.

We propose a model for BS and $M$ cell development that is supported by all of our data. The simplest hypothesis is that BS and $M$ cell development is regulated independently. In this situation, RuBPCase and ME accumulation would be induced earlier than PEPCase accumulation in normal leaves. A defective BS cell inducer in ar leaves would result in BS cell maturation being delayed with respect to $M$ cell maturation. This theory, however, implies the absence of cell-cell interactions. Because BS and $M$ cells in ar leaves always develop in clusters rather than randomly across the leaf, we believe such interactions must exist. If this is true, a more complex process has to be postulated. For example, a dual repressor/stimulator could act /either with or without a $M$ cell-specific factor) to repress PEPCase accumulation in $M$ cells yet interact with a BS cell-specific factor to induce RuBPCase and ME accumulation in BS cells. The increase in steady-state levels of BS cell-specific transcripts could turn off the repressor in $M$ cells, permitting accumulation of PEPCase. This would cause BS cell maturation to occur prior to $M$ cell maturation in normal leaves. If the production of the effector was defective or delayed such that only small amounts were produced, it would only accumulate in a few cells (presumably the oldest). This would result in the accumulation of RuBPCase and ME transcripts in only those few cells. The reduced amount of effector would result in partial derepression of PEPCase accumulation. $M$ cell maturation would therefore be advanced with respect to BS cell maturation, as seen in ar leaves. Because ar exhibits a temperature-sensitive phenotype, the effector would be defective only at low temperatures. Many other possibilities obviously exist.

\section{Methods}

\section{Plant material and growth conditions}

Experiments were carried out with an inbred line of Zea mays (Pioneer B73), a homozygous recessive greening mutant (ar) that had been backcrossed into the B73 background twice, and a segregating, selfed ar/B73 stock. Seeds were grown in rich soil, as described previously (Langdale et al. 1987). When grown for 21 days after planting, normal and ar third-leaf blades reached sizes of 15 and $11 \mathrm{~cm}$, respectively. At this time, both plants had initiated the same number of leaves. Experiments were carried out with leaf sheaths and immature third-leaf blades from these plants. Some in situ experiments were carried out using seedlings 7 days after planting. At this stage, leaves had only just emerged from the coleoptile. To minimize starch content in the chloroplasts, all seedlings used for in situ analysis were kept in the dark for $16 \mathrm{hr}$ prior to harvest.

Both inbred line B73 seedlings and wild-type siblings from segregating ar stocks were used as normal controls. No quantitative or qualitative differences in gene expression were observed between these stocks when $\mathrm{C} 4$ enzyme levels were compared by Western blot analysis (data not shown). Similarly, no differences were seen between ar seedlings from a segregating stock and those from a nonsegregating stock (data not shown). All data in this report show results obtained with inbred line (B73) normal controls and homozygous, nonsegregating ar stocks.

\section{Immunolocalization assays}

Immunolocalization assays were carried out as described previously (Langdale et al. 1987).

\section{Preparation of $c D N A$ probes}

cDNA subclones of maize RuBPCase Ssu, Lsu, and PEPCase were denoted pIL10, pIL12, and pTN1, respectively. All were subcloned by standard procedures (Maniatis et al. 1982) into the plasmid vector $\mathrm{pBS} \mid+$ ) |Stratagene cloning systems, San Diego, California). This vector positions the DNA insert between T3 and T7 RNA polymerase promoters. pJL10 contains a 460 bp PstI fragment of maize Ssu cDNA (isolation described in Nelson et al. 1984), pJL12 contains a 570-bp PstI fragment of maize Lsu cDNA (isolated from a cDNA clone described in Martineau and Taylor 1985), and pTNl contains a 660-bp PstI fragment of maize PEPCase cDNA isolated from pPC2 (Harpster and Taylor 1986). Lsu cDNA was a kind gift from Dr. William Taylor (University of California, Berkeley) and pPC2 was provided by Dr. Mark Harpster (Advanced Genetic Sciences, Oakland, California). 
Maize ME cDNA was isolated from a $\lambda \mathrm{gt} 11 \mathrm{cDNA}$ expression library, constructed and screened essentially according to Huynh et al. (1985). Poly $(\mathrm{A})^{+}$RNA was prepared, as described below, from inbred line B73 seedlings that had been grown in constant darkness for 7 days and then shifted to a 14-hr light/ 10 hr dark cycle for 2 days. The library was prepared using $2 \mu \mathrm{g}$ poly $(\mathrm{A}){ }^{+}$RNA and initially contained $80 \%$ recombinant phage in $4 \times 10^{5}$ plaque-forming units (pfu). Amplification resulted in a final titer of $5 \times 10^{10} \mathrm{pfu}, 55 \%$ of which were recombinant. Recombinant protein was detected on nitrocellulose lifts using NADP-ME primary antibody, goat anti-rabbit IgG horseradish peroxidase conjugate, and 4-chloro-1-naphthol, as described previously (Langdale et al. 1987).

The ME recombinant phage contained a $1.5-\mathrm{kb}$ insert that was subcloned into $\mathrm{pBS}|+|$ and denoted $\mathrm{pBF} 1$. Hybrid selection translation of this subclone was carried out using total leaf RNA according to Bunemann et al. (1982). A 560-bp internal PstI-HincII fragment of this cDNA was subcloned into pBS $\mid+1$ and denoted pTN5. All Northern blot analyses and in situ experiments were carried out using pTN5 as a ME cDNA clone.

\section{Preparation of RNA}

Isolated BS and M cells were prepared according to Sheen and Bogorad (1985). The purity and intactness of separated cells was assessed microscopically. BS cell preparations were normally contaminated with epidermal cells. RNA was prepared from separated cell types, also as described by Sheen and Bogorad (1985). Whole leaf RNA was prepared as described previously (Nelson et al. 1984 ). Poly(A) + RNA was purified using Hybond mAP paper (Amersham, Arlington Heights, Illinois), as recommended by the manufacturer. RNA was electrophoresed on $1 \%$ formaldehyde agarose gels and transferred to nitrocellulose, as described previously (Nelson et al. 1984). Purified cDNA fragments were labeled by random priming using hexadeoxyribonucleotides (Pharmacia, Piscataway, New Jersey) and $\left[{ }^{32} \mathrm{P}\right] \mathrm{dCTP}$ (3000 Ci/mmole ${ }^{1}$, Amersham) (Feinberg and Vogelstein 1984). Hybridizations were carried out overnight at $65^{\circ} \mathrm{C}$ in $5 \times$ SSC, $0.1 \%$ SDS, $0.1 \%$ sodium pyrophosphate, $5 \times$ Denhardt's (Denhardt 1966), and $200 \mu \mathrm{g} / \mathrm{ml}^{1}$ sonicated, denatured salmon sperm DNA. Filters were washed twice for $30 \mathrm{~min}$ each at $65^{\circ} \mathrm{C}$ in $1 \times$ SSC, $0.1 \%$ SDS, and $0.1 \%$ sodium pyrophosphate and air-dried. Autoradiography was carried out using Kodak XAR-5 film (Eastman Kodak, Rochester, New York) and intensifying screens.

\section{In situ hybridization}

Fresh leaf tissue was fixed, embedded in Paraplast Plus, and sectioned as described previously (Langdale et al. 1987). Sections were kept on slides at $4^{\circ} \mathrm{C}$ for up to a month before use. ${ }^{35} \mathrm{~S}$-Labeled riboprobes were synthesized using linearized cDNA subclones, ${ }^{35}$ S JUTP (1300 Ci/mmole ${ }^{1}$, New England Nuclear, Boston, Massachusetts), and T3 and T7 RNA polymerases (BRL, Bethesda, Maryland). Transcription reactions were carried out according to Ingham et al. (1985), with one modification. To maintain a high specific activity without sacrificing probe length $\left[{ }^{35} \mathrm{~S}\right] \mathrm{UTP}$ was dried down and transcription reactions were carried out in a volume of $5 \mu$ l. Hybridization reactions, washes, and autoradiography were carried out according to Ingham et al. (1985), with the exception that samples were treated with proteinase $\mathrm{K}$ for $30 \mathrm{~min}$ at $37^{\circ} \mathrm{C}$ instead of with pronase. Autoradiographs were counterstained for $1 \mathrm{~min}$ with $0.5 \%$ Fast Green FCF (Sigma, St. Louis, MO) in $95 \%$ ethanol, rinsed in ethanol, and incubated in xylenes for $5 \mathrm{~min}$. Samples were mounted in Permount and photographed using a Leitz Orthoplan II microscope and Kodak Tech Pan 2415 film.

\section{Acknowledgments}

We thank our colleagues Mary Metzler, Erin Irish, and Jychian Chen for many useful discussions throughout the course of this work. We are grateful to Steve Dellaporta for critically reading this manuscript, and we thank Belinda Martineau and Bill Taylor for making their in situ protocol available to us prior to publication. This work was supported by an individual award from the McKnight Foundation and by National Institutes of Health grant GM33984 to T.N. B.A.R. is the recipient of a National Institutes of Health predoctoral training fellowship.

\section{References}

Aoyagi, K. and J.A. Bassham. 1986. Appearance and accumulation of $\mathrm{C} 4$ carbon pathway enzymes in developing wheat leaves. Plant Physiol. 80: 334-340.

- 1986b. Appearance and accumulation of C4 carbon pathway enzymes in developing maize leaves and differentiating maize A188 callus. Plant Physiol. 80: 322-333.

Aoyagi, K. and H. Nakamoto. 1985. Pyruvate Pi dikinase in bundle sheath strands as well as in mesophyll cells in maize leaves. Plant Physiol. 78: 661-664.

Baker, N.R. and R.M. Leech. 1977. Development of photosystem I and photosystem II activities in leaves of light grown maize (Zea mays). Plant Physiol. 60: 640-644.

Broglie, R., G. Coruzzi, B. Keith, and N.-H. Chua. 1984. Molecular biology of $\mathrm{C} 4$ photosynthesis in Zea mays: Differential localization of proteins and mRNAs in the two leaf cell types. Plant Mol. Biol. 3: 431-444.

Brown, W.V. 1975. Variations in anatomy, associations, and origins of Kranz tissue. Am. J. Bot. 62: 395-402.

Bunemann, H., P. Westhoff, and R.G. Herrmann. 1982. Immobilization of denatured DNA to macroporous supports: 1 . Efficiency of different coupling procedures. N.A.R. 10: $7163-7180$.

Collins, P.D. and D.R. Hague. 1983. Light-stimulated synthesis of NADP malic enzyme in leaves of maize. J. Biol. Chem. 258: $4012-4018$.

Dean, C. and R.M. Leech. 1982. Genome expression during normal leaf development. Plant Physiol. 69: 904-910.

Dengler, N.G., R.E. Dengler, and P.W. Hattersley. 1985. Differing ontogenetic origins of PCR (Kranz) sheaths in leaf blades of C4 grasses (Poaceae). Am. J. Bot. 72: 284-302.

Denhardt, D.T. 1966. A membrane filter technique for the detection of complimentary DNA. Biochem. Biophys. Res. Commun. 23: 641-646.

Edwards, G.E. and S.C. Huber. 1979. C4 metabolism in isolated cells and protoplasts. In Photosynthesis $I I$ (ed. M. Gibbs and E. Latzkol, pp. 102-112. Springer-Verlag, Berlin.

1981. The C4 pathway. In Biochemistry of Plants (ed. M.D. Hatch and N.K. Boardman), vol. 8, pp. 238-281. Academic Press, New York and London.

Esau, K. 1942. Ontogeny of the vascular bundle in Zea mays. Hilgardia 15: 327-368.

Eyster, W.H. 1933. Plastid studies in genetic types of maize: Argentia chlorophyll. Plant Physiol. 8: 105-122.

Feinberg, A.P. and B. Vogelstein. 1984. A technique for radiolabelling DNA restriction endonuclease fragments to high specific activity. Anal. Biochem. 137: 266-267.

Harpster, M.H. and W.C. Taylor. 1986. Maize phosphoenolpyruvate carboxylase. Cloning and characterization of mRNAs 
encoding isozymic forms. J. Biol. Chem. 261: 6132-6136.

Huynh, T.V., R.A. Young, and R.W. Davis. 1985. Constructing and screening cDNA libraries in lambda gt 10 and lambda gt11. In DNA cloning Volume 1; a practical approach. (ed. D.M. Glover), pp. 49-78. IRL Press, Oxford and Washington.

Ingham, P., K.R. Howard, and D. Ish-Horowicz. 1985. Transcription pattern of the Drosophila segmentation gene hairy. Nature 318: 439-445.

Laetsch, W.M. and I. Price. 1969. Development of the dimorphic chloroplasts of sugar cane. Amer. J. Bot. 56: 77-87.

Langdale, J.A., M.C. Metzler, and T. Nelson. 1987. The argentia mutation delays normal development of photosynthetic cell-types in Zea mays. Dev. Biol. 122: 243-255.

Link, G., D.M. Coen, and L. Bogorad. 1978. Differential expression of the gene for the large subunit of ribulose bisphosphate carboxylase in maize leaf cell types. Cell 15: 725-731.

Leese, R.M. and R.M. Leech. 1976. Sequential changes in the lipids of developing proplastids isolated from greening maize leaves. Plant Physiol. 57: 789-794.

Maniatis, T., E.F. Fritsch, and J. Sambrook. 1982. Molecular cloning: A laboratory manual. Cold Spring Harbor Laboratory, Cold Spring Harbor, New York.

Martineau, B. and W.C. Taylor. 1985. Photosynthetic gene expression and cellular differentiation in developing maize leaves. Plant Physiol. 78: 399-404.

__ 1986. Cell-specific gene expression in maize determined using cell separation techniques and hybridization in situ. Plant Physiol. 82: 613-618.

Mayfield, S.P. and W.C. Taylor. 1984. The appearance of photosynthetic proteins in developing maize leaves. Planta 161: $481-486$.

Miranda, V., N.R. Baker, and S.P. Long. 1981. Anatomical variation along the length of the Zea mays leaf in relation to photosynthesis. New Phytol. 88: 595-605.

Nelson, T., M.H. Harpster, S.P. Mayfield, and W.C. Taylor. 1984. Light regulated gene expression during maize development. J. Cell Biol. 98: 558-564.

Russell, S.H. and R.F. Evert. 1985. Leaf vasculature in Zea mays. Planta 164: 448-458.

Sharman, B.C. 1942. Developmental anatomy of the shoot of Zea mays L. Ann. Bot. 6: 245-284.

Sheen, J.-Y. and L. Bogorad. 1985. Differential expression of the ribulose bisphosphate carboxylase large subunit gene in bundle sheath and mesophyll cells of developing maize leaves is influenced by light. Plant Physiol. 79: 1072-1076.

. 1986. Expression of the ribulose-1,5-bisphosphate carboxylase large subunit gene and three small subunit genes in two cell types of maize leaves. EMBO I. 5: 3417-3422.

Taylor, J.A. and R.O. Mackender. 1977. Plastid development in the first leaf of Avena sativa L. Plant Physiol. 59: 5-10.

Viro, M. and K. Kloppstech. 1980. Differential expression of genes for ribulose 1,5 bisphosphate carboxylase and light harvesting chl $\mathrm{a} / \mathrm{b}$ protein in the developing barley leaf. Planta 150: $41-45$.

Williams, L.E. and R.A. Kennedy. 1978. Photosynthetic carbon metabolism during leaf ontogeny in Zea mays L: Enzyme studies. Planta 142: 269-274. 


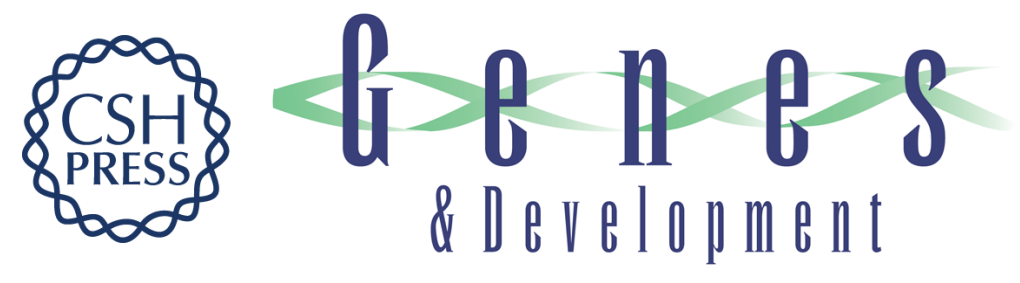

\section{Cellular pattern of photosynthetic gene expression in developing maize leaves.}

J A Langdale, B A Rothermel and T Nelson

Genes Dev. 1988, 2:

Access the most recent version at doi:10.1101/gad.2.1.106

References This article cites 32 articles, 13 of which can be accessed free at: http://genesdev.cshlp.org/content/2/1/106.full.html\#ref-list-1

License

Email Alerting

Receive free email alerts when new articles cite this article - sign up in the box at the top Service right corner of the article or click here.

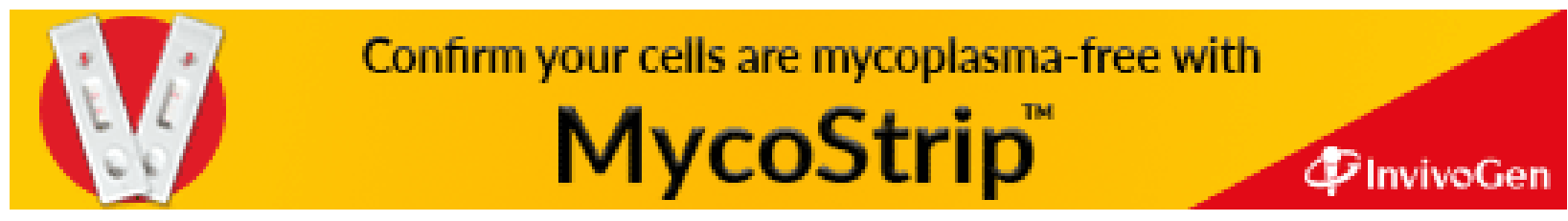

